\title{
Effect of temperature and moisture content on tensile behaviour of false banana fibre (Ensete ventricosum)**
}

\author{
Cestmir Mizera ${ }^{*}$, David Herak ${ }^{1}$, Petr Hrabe ${ }^{2}$, and Abraham Kabutey ${ }^{1}$ \\ ${ }^{1}$ Department of Mechanical Engineering, ${ }^{2}$ Department of Material Sciences and Manufacturing Technology; \\ Faculty of Engineering, Czech University of Life Sciences Prague, Kamycka 129, Prague, Czech Republic
}

Received October 10, 2016; accepted June 27, 2017

\begin{abstract}
A b s t r a c t. The mechanical behaviour of natural fibres as composite materials can be affected by changes in temperature and moisture content. The aim of this paper was to describe the effect of temperature and moisture content on tensile strength of false banana fibre (Ensete ventricosum) and to determine its water absorption. Samples of fibres were prepared and tested until rupture point with strain rate of $0.05 \mathrm{~min}^{-1}$ at temperature change between -20 and $220^{\circ} \mathrm{C}$ as well as moisture content between 10 and $90 \% \mathrm{wb}$. The water absorption and release of Ensete fibres at 60 and $90 \%$ relative humidity was also determined. Results showed that Ensete fibres exhibited stability of tensile strength in the temperature range from 0 to $100^{\circ} \mathrm{C}$ but the increase of temperature decreased statistically significantly the tensile strength. The effect of moisture content on tensile strength was not statistically significant. The equilibrium moisture content at $60 \%$ relative humidity and $25^{\circ} \mathrm{C}$ was determined.

K e y w o r d s: stress, tensile testing, water absorption, plant material
\end{abstract}

\section{INTRODUCTION}

Ecological concern has resulted in a profound interest in renewable materials. Lignocellulosic natural fibres such as hemp, sisal, banana, jute and flax are interesting, environmentally friendly, alternative synthetic polymeric fibres for application in engineering composites (Aseer, 2013). The natural fibres are biodegradable, recyclable, nonabrasive, environmentally friendly, and contribute to a reduction of waste and environmental pollution (Faruk et al., 2012; Kalia et al., 2013; Rao et al., 2007; Silva et al., 2008). They also exhibit excellent mechanical properties, low density, and they are available in fibrous forms at

*Corresponding author e-mail: mizera@tf.czu.cz

**This work was supported by Internal Grant Agency of Faculty of Engineering, Czech University of Life Sciences, Prague - IGA 2017:31130/1312/3111. low cost (Aseer, 2013). This excellent price-performance ratio at low density in connection with the environmentally friendly character is very important for the acceptance of natural fibres in large volume engineering applications such as the automotive and construction industry (Stamboulis et al., 2001).

Another suitable plant with great potential for the production of natural fibres is Ensete (Ensete ventricosum), also known as false banana (Tsehaye and Kebebew, 2006; Yemataw et al., 2014). The Ensete plant does not bear edible fruits and it is not categorised as usual banana plants (genera Musa). Some studies on the mechanical properties of Ensete fibres have been published. For instance, the authors Mizera et al. (2016) reported the effect of length of fibre on mechanical behaviour under tensile load. However, one of the most important considerations using natural fibres as a construction material is the effect of temperature and moisture content on the mechanical properties (Bledzki and Gassan, 1999; Stoclet et al., 2011). Indeed, due to the nature of the cell wall constituents, temperature has a strong influence on the mechanical properties of plant fibres (Bourmaud et al., 2016). Studies of the authors Baley et al. (2012) showed that the tensile strength of flax fibre after heating for $14 \mathrm{~h}$ at $105^{\circ} \mathrm{C}$ was strongly affected by the drying cycle which resulted in damage to the fibres. In the production of new composite materials a new bio-based polymer is used, such as Polyamide 11 (PA11). The combination of PA11 with natural fibres could be limited due to its high melting temperature (Stoclet et al., 2011), thus imposing a process temperature between 200 and $230^{\circ} \mathrm{C}$ (Jolly et al., 2002;

(C) 2017 Institute of Agrophysics, Polish Academy of Sciences 
Lafitte et al., 2011). In addition the authors Faruk et al., (2012), Müssig (2010), Rao and Rao (2007), Stamboulis et al. (2001), confirmed that the moisture content of natural fibres had a great effect on the mechanical properties of fibres. Therefore it is very important to determine the effect of temperature and moisture content on the mechanical behaviour of Ensete fibres. However, currently, this effect is not adequately described. The aim of this experiment was to describe the effect of temperature and moisture content on tensile strength of Ensete fibres and to determine their water absorption.

\section{MATERIALS AND METHODS}

Samples of fibres (Fig. 1) produced from Ensete ventricosum, obtained from Hawassa region, Ethiopia, were used for the experiment. The moisture content $10.48 \pm 0.93 \%$ (w.b.) of the samples was determined using ASAE method (ASAE S410.1 DEC97), (ASAE, 1998). From a batch of Ensete fibres, samples of $100 \mathrm{~g}$ mass were randomly selected for moisture content determination. The mass of each sample $m_{s}(\mathrm{~g})$ was determined using an electronic balance (Kern 440-35, Kern and Sohn GmbH, Balingen, Germany). The results obtained were expressed as mean of three replicates.

The compression device (Labortech, MPTest 5.050, Czech Republic) was used to record the course of tension force and deformation of the samples. The selected samples of Ensete fibres were inserted into grips of the testing machine with gauge length $\left(L_{0}\right)$ of $20 \mathrm{~mm}$. The tests were carried out for varying temperatures $(\mathrm{T})$ of $-20,0$, $20,40,60,80,100,140,180$ and $220 \pm 5^{\circ} \mathrm{C}$. The temperature was set on the testing chamber (Labortech, TH2700 Standard, Czech Republic). Each fibre was tempered $10 \mathrm{~min}$ before the test representing thermal cycles used for production of composites which have been indicated by some authors (Bourmaud and Baley, 2010). The fibres were tested until rupture, using strain rate of $0.05 \mathrm{~min}^{-1}$. The experiment was repeated twenty times for each temperature of fibres.

The tests were carried out at several values of moisture content (Mc) of 10, 20, 40, 60, 80 and $90 \pm 5 \%$. Samples of fibres were harvested at natural moisture content and were gradually dried in a laboratory oven for different moisture content. The fibres with corresponding moisture content

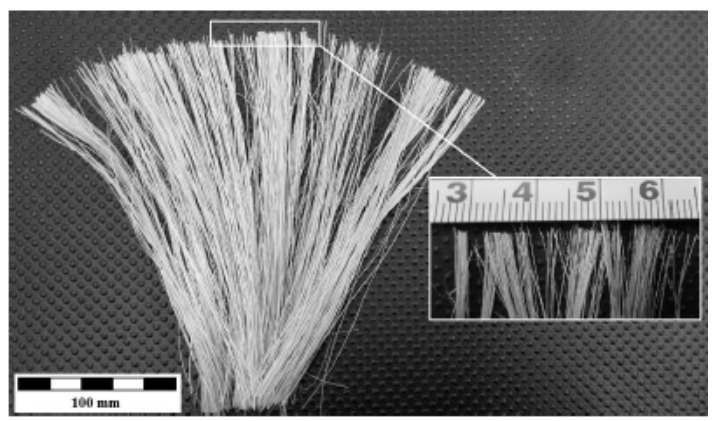

Fig. 1. Ensete ventricosum fibres. were inserted into the grips of the testing machine. The fibres were tested until rupture, using strain rate of 0.05 $\mathrm{min}^{-1}$. The experiment was repeated twenty times for each level of moisture content of fibres.

Statistica software (Statsoft, 2010) was used to analyse the experimental data. Measured values were verified using one-way analysis of variance (ANOVA) at significance level 0.05 .

Moisture absorption of Ensete fibres was studied. Prior to testing, the fibres were dried in an oven at $70^{\circ} \mathrm{C}$ for $24 \mathrm{~h}$, as reported by some authors (Stamboulis et al., 2001). The humid environment was prepared with the use of an airconditioned oven (Memmert HCP 108, Memmert GmbH + $\mathrm{CO}, \mathrm{KG}$, Germany). Bundles of fibres were kept together and inserted in the oven at $25^{\circ} \mathrm{C}$ and 60 and $90 \%$ relative humidity $(\mathrm{RH})$. To ensure the final moisture content, the specimens were weighed at regular intervals.

The fibres were analysed for fibre diameter by image analysis using an optical microscope (Zeiss Jenavert, Carl Zeiss, Jena, Germany). The dimensions were determined at 10 points on each fibre before the tension test.

The fibre cross section area $(S)$ was calculated by Eq. (1):

$$
S=\frac{\pi D^{2}}{4},
$$

where: $D$ is diameter of fibre $(\mathrm{mm})$.

The determined amounts of tension force and deformation were transformed into stress and strain using Eqs (2) and (3), respectively:

$$
\begin{aligned}
& \sigma=\frac{F}{S}, \\
& \varepsilon=\frac{x}{L_{0}},
\end{aligned}
$$

where: $\sigma$ is stress of fibre (MPa), $S$ is appropriate cross section area of fibre $\left(\mathrm{mm}^{2}\right), \varepsilon$ is strain, $x$ is elongation of fibre $(\mathrm{mm}), L_{0}$ is initial length of fibre $(\mathrm{mm})$.

\section{RESULTS AND DISCUSSION}

For each fibre the dependency between tension force and elongation was recorded and transformed into stress strain curve using Eqs (2) and (3). The average values of tensile strength for each level of temperature and moisture content of Ensete fibres are shown in Tables 1 and 2, as well as their statistical analysis in Tables 3 and 4, respectively. Figs 2 and 3 present also their graphical relationships. In addition, the average values of strain at failure for different levels of moisture content are presented in Fig. 4, and the curves of moisture uptake and release as a function of time for 60 and $90 \%$ relative humidity are presented in Fig. 5. It is evident in Table 1 or Fig. 2 that the environmental temperature had a limited effect on the tensile strength of Ensete fibres. A decrease in the performance of Ensete fibres was observed at the minus temperature, and a peak 
T a b l e 1. Mechanical properties of Ensete fibre under different temperature

\begin{tabular}{cccc}
\hline $\mathrm{T}\left({ }^{\circ} \mathrm{C}\right)$ & $\sigma_{\mathrm{F}}(\mathrm{MPa})$ & $\Delta L_{F}(\mathrm{~mm})$ & $\varepsilon_{F}$ \\
\hline-20 & $452 \pm 54$ & $0.62 \pm 0.14$ & $0.031 \pm 68210^{-5}$ \\
0 & $483 \pm 68$ & $0.44 \pm 0.08$ & $0.022 \pm 41810^{-5}$ \\
25 & $526 \pm 63$ & $0.50 \pm 0.13$ & $0.025 \pm 65010^{-5}$ \\
40 & $474 \pm 90$ & $0.42 \pm 0.11 \pm 52510^{-5}$ \\
60 & $498 \pm 85$ & $0.54 \pm 0.12$ & $0.027 \pm 62110^{-5}$ \\
80 & $477 \pm 105$ & $0.66 \pm 0.12$ & $0.033 \pm 59410^{-5}$ \\
100 & $485 \pm 68$ & $0.52 \pm 0.11$ & $0.026 \pm 57210^{-5}$ \\
180 & $378 \pm 64$ & $0.40 \pm 0.11$ & $0.020 \pm 54010^{-5}$ \\
220 & $339 \pm 75$ & $0.66 \pm 0.20$ & $0.033 \pm 102310^{-5}$ \\
\hline
\end{tabular}

$\mathrm{T}-$ temperature of fibres, $\sigma_{\mathrm{F}}$ - rupture stress, $\Delta L_{F}$ - rupture elongation, $\varepsilon_{F}-$ rupture strain. Data in the table are means $\pm \mathrm{SD}$.

T a b l e 2. Mechanical properties of Ensete fibre under different moisture content

\begin{tabular}{cccc}
\hline Mc $(\%)$ & $\sigma_{\mathrm{F}}(\mathrm{MPa})$ & $\Delta L_{F}(\mathrm{~mm})$ & $\varepsilon_{F}$ \\
\hline 10 & $492 \pm 59$ & $0.44 \pm 0.07$ & $0.022 \pm 37410^{-5}$ \\
20 & $525 \pm 84$ & $1.06 \pm 0.16$ & $0.053 \pm 79510^{-5}$ \\
40 & $540 \pm 65$ & $1.42 \pm 0.23$ & $0.071 \pm 113610^{-5}$ \\
60 & $590 \pm 100$ & $1.78 \pm 0.39$ & $0.089 \pm 195810^{-5}$ \\
80 & $497 \pm 85$ & $2.68 \pm 0.38$ & $0.134 \pm 187610^{-5}$ \\
90 & $468 \pm 103$ & $2.78 \pm 0.67$ & $0.139 \pm 333610^{-5}$ \\
\hline
\end{tabular}

$\mathrm{Mc}-$ moisture content of fibres $\pm 5 \%$. Other explanations as in Table 1 .

T a b l e 3. Statistical analysis ANOVA, comparison with values of room temperature $\left(25^{\circ} \mathrm{C}\right)$

\begin{tabular}{cccc}
\hline $\mathrm{T}\left({ }^{\circ} \mathrm{C}\right)$ & $\mathrm{F}_{\text {rat }}$ & $\mathrm{F}_{\text {crit }}$ & $\mathrm{P}_{\text {value }}$ \\
\hline-20 & 11.312 & 4.098 & 0.99 \\
0 & 3.054 & 4.098 & 0.91 \\
40 & 3.789 & 4.098 & 0.90 \\
60 & 1.758 & 4.098 & 0.98 \\
80 & 2.457 & 4.098 & 0.99 \\
100 & 2.687 & 4.098 & 0.98 \\
140 & 37.678 & 4.098 & 0.99 \\
180 & 74.605 & 4.098 & 0.99 \\
220 & 250.211 & 4.098 & 0.99 \\
\hline
\end{tabular}

$\mathrm{F}_{\text {rat }}-$ value of the $\mathrm{F}$ test, $\mathrm{F}_{\text {crit }}-$ critical value that compares a pair of models, $\mathrm{P}_{\text {value }}-$ significant level of the study hypothesis. Other explanations as in Table 1. was seen near room temperature. In the temperature range up to $100^{\circ} \mathrm{C}$ no major changes of tensile strength were observed, as confirmed by the statistical analysis ANOVA results (Table 2) at significance level 0.05. A greater loss in tensile strength occurred at higher temperatures due to the loss of water (van Voorn et al., 2001). The mechanical properties of Ensete fibres attained good stability, but a gradual significant decline began above $140^{\circ} \mathrm{C}$. The degradation in strength at failure reached 22.0, 30.1, and 48.1\% after exposure to 140,180 , and $220^{\circ} \mathrm{C}$ in comparison with room temperature. A significant decrease in mechanical properties of other natural fibres at high temperatures has been indicated by some authors and mainly attributed to the evolution of the cell wall structure and organisation. For example, the authors Gassan and Bledzki (2001) and Placet (2009) reported structural degradation for flax and jute fibres above $170^{\circ} \mathrm{C}$. These changes in natural fibres may be caused by transition phenomena within the polymers which make up the plant cell walls (Gourier et al., 2014). Further, it could be due to a progressive and irreversible 
T a b l e 4. Statistical analysis ANOVA, comparison with near values of equilibrium moisture content $(10 \%$ d.b.)

\begin{tabular}{cccc}
\hline $\mathrm{Mc}(\%)$ & $\mathrm{F}_{\text {rat }}$ & $\mathrm{F}_{\text {crit }}$ & $\mathrm{P}_{\text {value }}$ \\
\hline 20 & 2.265 & 4.098 & 0.96 \\
40 & 3.354 & 4.098 & 0.97 \\
60 & 3.897 & 4.098 & 0.95 \\
80 & 1.758 & 4.098 & 0.99 \\
90 & 2.175 & 4.098 & 0.98 \\
\hline
\end{tabular}

Other explanations as in Tables 2 and 3. modification of the biochemical structure responsible for interactions with water molecules, such as pectins, hemicellulose or even non-crystalline fibrillar cellulose (Gourier et al., 2014). The authors Gassan and Bledzki (2001) also confirmed that the structural properties of cellulose, hemicelluloses and pectins may be altered by high temperatures. Measurements over the moisture content range of 10 to $90 \%$ (w.b.) showed no severe loss of tensile strength of Ensete fibres, as confirmed by the statistical analysis ANOVA results (Table 4) at significance level 0.05. But, the strain at failure showed a significant difference. Placet (2009) also confirmed that the strain at failure increased with moisture content of hemp fibres. In Fig. 5, Ensete fibres at room temperature contained approximately $11.8 \%$ d.b. water at $60 \% \mathrm{RH}$ and $25^{\circ} \mathrm{C}$ of which $1.6 \%$ was bound

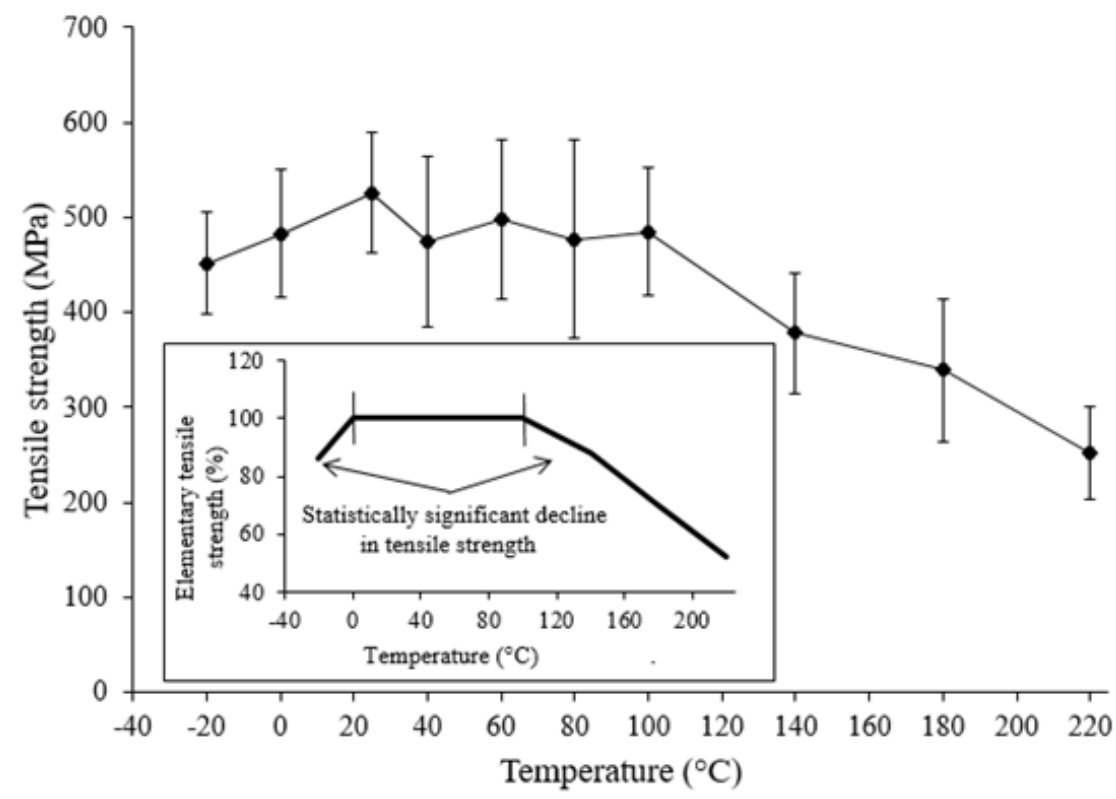

Fig. 2. Tensile strength of Ensete fibres under different temperatures (bars represent standard deviation of the mean $\pm \mathrm{SD}, \mathrm{p}<0.05$ ).

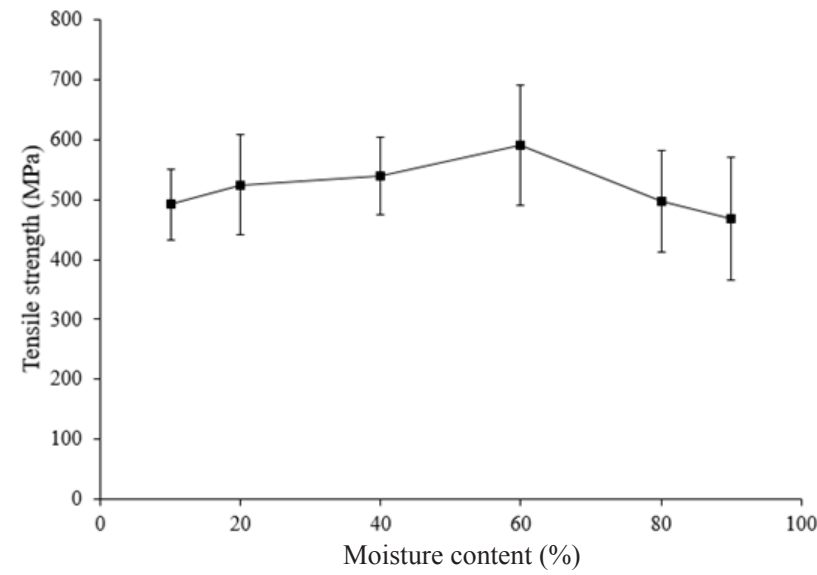

Fig. 3. Tensile strength of Ensete fibres under different moisture content. Explanations as in Fig. 2.

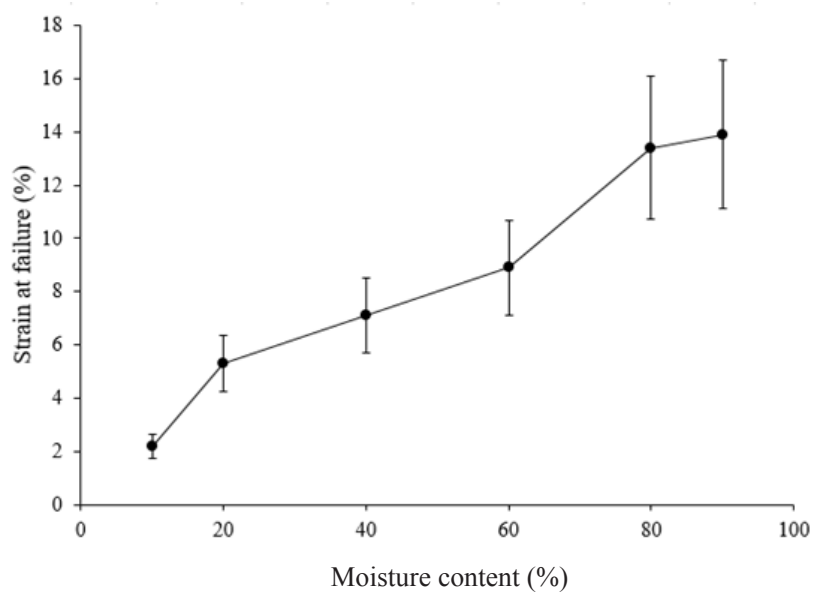

Fig. 4. Strain at failure of Ensete fibres under different moisture content. Explanations as in Fig. 2. 


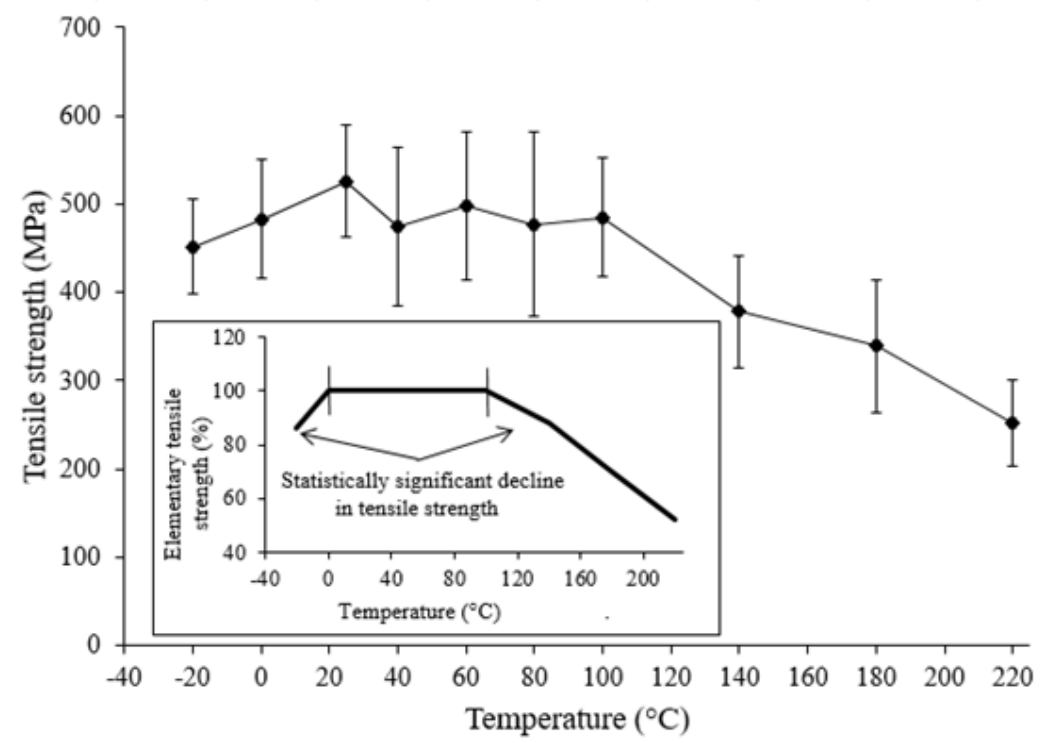

Fig. 5. Moisture uptake and release of Ensete fibres - uptake at $25^{\circ} \mathrm{C}$ after drying at $70^{\circ} \mathrm{C}$ and release after conditioning at $90 \% \mathrm{RH}$, $25^{\circ} \mathrm{C}$. Explanations as in Fig. 2.

to the fibres (Hatakeyama, 1987). After drying at $70^{\circ} \mathrm{C}$ for $6 \mathrm{~h}$ the fibres had $1.6 \%$ w.b. moisture. The value $11.8 \%$ w.b. was described as the equilibrium moisture content. Similar result was also determined for jute, sisal and pineapple fibres (Rowell, 2008). Lower sensitivity of water absorption has been known for flax and bamboo fibres (7-9\% w.b.), whereas higher sensitivity of water absorption (about 15\% w.b.) has been found for abaca fibres (Rowell, 2008). From Fig. 5, it is evident that the uptake or absorption of water at room temperature started very quickly, therefore there was a limited time for the transfer of the dried fibres from the oven to the matrix as related to the manufacture of composites. This hydrophilic nature of fibres is a major problem for all cellulose fibres for application as reinforcement in composites. The moisture content of the fibres was dependent on the content of non-crystalline parts and the void content of the fibres (Faruk et al., 2012).

\section{CONCLUSIONS}

1. False banana fibre (Ensete ventricosum) exhibited stability of tensile strength in the temperature range from 0 to $100^{\circ} \mathrm{C}$ but the increase of temperature decreased statistically significantly the tensile strength.

2. Tensile strength above $140^{\circ} \mathrm{C}$ declined and reached 22.0, 30.1, and 48.1\% degradation after exposure to 140 , 180 , and $220^{\circ} \mathrm{C}$, respectively.

3. The effect of moisture content on tensile strength was not statistically significant.

4. The results of mechanical behaviour of Ensete fibres determined in this study are useful for application in engineering composite materials.

Conflict of interest: The Authors do not declare conflict of interest.

\section{REFERENCES}

ASAE S410.1 DEC97, 1998. Moisture measurement of peanut. In: ASAE standards, 45th edition. 560-561.

Aseer J.R., Sankaranarayanasamy K., Jayabalan P., Natarajan R., and Dasan K.P., 2013. Morphological, Physical and thermal properties of chemically treated banana fiber. J. Natural Fibers, 10, 365-380.

Baley C., Le Duigou A., Bourmaud A., and Davies P., 2012. Influence of drying on the mechanical behaviour of flax fibres and their unidirectional composites. Composites: Part A, 43, 1226-1233.

Bledzki A.K. and Gassan J., 1999. Composites reinforced with cellulose based fibres. Progress in Polymer Sci., 24, 221-274.

Bourmaud A. and Baley C., 2010. Effects of thermo mechanical processing on the mechanical properties of biocomposite flax fibers evaluated by nanoindentation. Polymer Degradation and Stability, 95, 1488-1494.

Bourmaud A., Le Duigou A., Gourier C., and Baley C., 2016. Influence of processing temperature on mechanical performance of unidirectional polyamide 11-flax fibre composites. Industrial Crops and Products, 84, 151-165.

Faruk O., Bledzki A.K., Fink H.P., and Sain M., 2012. Biocomposites reinforced with natural fibers: 2000-2010. Progress in Polymer Sci., 37, 1552-1596.

Gassan J. and Bledzki A.K., 2001. Thermal degradation of flax and jute fibers. J. Applied Polymer Sci., 82, 1417-1422.

Gourier C., Le Duigou A., Bourmaud A., and Baley C., 2014. Mechanical analysis of elementary flax fibre tensile properties after different thermal cycles. Composites Part A: Applied Sci. Manufacturing, 64, 159-166.

Hatakeyama T., 1987. Effect of bound water on structural change of regenerated cellulose. Macromolecular Chemistry and Physics, 188, 1877-1884.

Jolly L., Tidu A., Heizmann J.J., and Bolle B., 2002. Microstructure evolution in polyamide PA11 under small uniaxial extension. Polymer, 43, 6839-6851. 
Kalia S., Thakur K., Celli A., Kiechel M.A., and Schauer C.L., 2013. Surface modification of plant fibers using environment friendly methods for their application in polymer composites, textile industry and antimicrobial activities. J. Environ. Chemical Eng., 1, 97-112.

Laffite G., Espuche E., and Gerard J.F., 2011. Polyamide 11/ poly(hydroxy amino ether) blends: Influence of the blend composition and morphology on the barrier and mechanical properties. European Polymer J., 47, 1994-2002.

Mizera Č., Herák D., Hrabě P., Müller M., and Kabutey A., 2016. Effect of length of false banana fibre (Ensete ventricosum) on mechanical behaviour under tensile loading. Scientia Agriculturae Bohemica, 47, 90-96.

Müssig J., 2010. Industrial application of natural fibres: structure, properties, and technical applications. Wiley Press, Chichester, England.

Placet V., 2009. Characterization of the thermo-mechanical behaviour of Hemp fibres intended for the manufacturing of high performance composites. Composites Part A: Applied Sci. Manufacturing, 40, 1111-1118.

Placet V., Cisse O., and Boubakar M.L., 2012. Influence of environmental relative humidity on the tensile and rotational behaviour of hemp fibres. J. Materials Sci., 47, 3435-3446.

Rao K.M.M. and Rao K.M., 2007. Extraction and tensile properties of natural fibers: Vakka, date and bamboo. Composite Structures, 77, 288-295.
Rowell R.M., 2008. Properties and performance of natural-fibre composites. A volume in Woodhead Publishing Series in Composites Sci. Eng., 3-66.

Silva F.A., Chawla N., and Filho R.D.T., 2008. Tensile behavior of high performance natural (sisal) fibers. Composites Sci. Technol., 68, 3438-3443.

Stamboulis A., Baillie C. A., and Peijs T., 2001. Effects of environmental conditions on mechanical and physical properties of flax fibers. Composites Part A: Applied Sci. Manufacturing, 32, 1105-1115.

Statsoft, 2010. Statsoft., Inc. Tulsa, OK74104, USA, 2010.

Stoclet G., Seguela R., and Lefebvre J.M., 2011. Morphology, thermal behavior and mechanical properties of binary blends of compatible biosourced polymers: Polylactide/ polyamide11. Polymer, 52, 1417-1425.

Tsehaye Y. and Kebebew F., 2006. Diversity and cultural use of Enset (Enset ventricosum (Welw.) Cheesman) in Bonga in situ Conservation Site, Ethiopia. Ethnobotany Res. Applications, 4, 147-157.

van Voorn B., Smit H.H.G., Sinke R.J., and de Klerk B., 2001. Natural fibre reinforced sheet moulding compound, Composites Part A: Applied Sci. Manufacturing, 32, 1271-1279.

Yemataw Z., Mohamed H., Diro M., Addis T., and Blomme G., 2014. Enset (Ensete ventricosum) clone selection by farmers and their cultural practices in southern Ethiopia. Genetic Resources and Crop Evolution, 61(6), 1091-1104. 